\title{
Thunderstorm Trends over Africa
}

\author{
MaAyan Harel AND Colin Price \\ Porter School of the Environment and Earth Sciences, Tel Aviv University, Tel Aviv, Israel
}

(Manuscript received 16 November 2018, in final form 18 December 2019)

\begin{abstract}
Thunderstorms inflict death and damage worldwide due to lightning, heavy rains, hail, and strong winds. While the effect of global warming on future thunderstorm activity is still debatable, this work investigates how thunderstorm activity over Africa may have changed over the last 70 years. Thunderstorm data were obtained from the World Wide Lightning Location Network (WWLLN) and processed to produce thunderstorm clusters. The number and area of clusters in one year (2013) were compared with several climate parameters tied to thunderstorm development, taken from the NCEP-NCAR Reanalysis-1 product (NCEP). The two parameters that correlated best with thunderstorm number were lifted index and specific humidity, with correlations of -0.795 and 0.779 , respectively. These parameters were used to construct an empirical model that predicts the number and area of thunderstorm clusters over Africa on a particular day, month, or year. The empirical model was run from 1948 to 2016, providing a reconstruction of long-term thunderstorm activity over Africa. The time series was compared to temperature data from NCEP, and showed that the number of clusters increased with rising surface temperature on annual and decadal time scales, particularly since the mid-1990s. On an annual time scale, the number and area of thunderstorm clusters exhibited a highly sensitive relationship with surface temperature, with a $\sim 40 \%$ increase in the number of thunderstorm clusters for every $1-\mathrm{K}$ rise in temperature over Africa. The correlation coefficients with surface temperature were 0.745 and 0.743 for cluster number and area, respectively, indicating that surface temperature explains $\sim 55 \%$ of the variability in interannual thunderstorm clusters over the past 70 years.
\end{abstract}

\section{Introduction}

Every hour, around 1000 thunderstorms dominate the tropical latitudes, where tropical Africa exhibits the highest flash rates (Christian 2003; Williams 2005) and the most mesoscale convective systems (MCSs) (Toracinta and Zipser 2001; Laing et al. 1999) and hosts 283 of the top 500 lightning hotspots on Earth (Albrecht et al. 2016). Lightning strikes cause injury, death, and damage to property, industry, and infrastructure, as well as forest fires. Rural populations are often the most vulnerable to the immediate dangers of direct strikes, and studies in several African countries have revealed high rates of injury and fatalities (Cooray et al. 2007; Dlamini 2009; Mary and Gomes 2012). This work focuses on African thunderstorms due to their frequency and intensity, as well as their role in the

Supplemental information related to this paper is available at the Journals Online website: https://doi.org/10.1175/JCLI-D-180781.s1.

Corresponding author: Maayan Harel, mharel.tau@gmail.com formation of Atlantic tropical cyclones (Price et al. 2007, 2015). Despite representing nearly $80 \%$ of total global lightning, relatively little research has focused on the impact of climate change on tropical and subtropical thunderstorms (Bond et al. 2002; Finney et al. 2018).

The degree to which lightning regimes are sensitive to climate change is still debatable. This question has implications in climate forecasting due to lightning's direct and indirect effects on radiative forcing and atmospheric chemistry through $\mathrm{NO}_{x}$ production (Forster and Shine 1997; Price et al. 1997; Schumann and Huntrieser 2007; Myhre et al. 2013; Banerjee et al. 2014) and thunderstorms' injection of water vapor into the upper troposphere (Price 2000; Williams 2005; Price and Asfur 2006a). Several studies suggest that the regions in which lightning is most sensitive to surface warming are the tropical landmasses, which are the most active in terms of lightning in the present climate (Williams 1992, 1994; Finney et al. 2018). Lightning can also be an important marker in the investigation of changes in the frequency and severity of extreme weather events that it accompanies (Brooks et al. 2003; Price et al. 2011; Brooks 2013). 
The historical record of global lightning activity is somewhat limited, as monitoring systems are constrained in space and/or time. In the absence of a complete record, variables with a direct relationship to lightning may be used to provide proxies (Brooks et al. 2003). Meteorological reanalysis datasets, like NCEP-NCAR reanalysis, produce continuous reconstructions of past atmospheric states, offering many options for the use of covariates to simulate past lightning activity. Further back in its time series, there are fewer observations assimilated into the reanalysis model. However, there are some observations, and therefore this dataset provides one of the best available spatially and temporally complete representations of the historical climate.

One of the difficulties in predicting changes in future lightning activity is knowing the parameters in the present climate that are best related to it. This work investigates the link between large-scale meteorological parameters and thunderstorm activity, in the interest of understanding how thunderstorm behavior changes over time.

Thunderstorm charging is widely believed to result from the noninductive charging mechanism, for which cloud ice and supercooled water have been shown to be fundamental components. Cloud electrification generally requires the presence of a mixed phase region where supercooled water droplets, ice crystals, and graupel undergo microphysical processes of riming, collisions, and other interactions that bring about charge separation in the cloud particles (Takahashi 1978; Toracinta and Zipser 2001). Rosenfeld and Woodley (2000) used in situ measurements in deep convective clouds, and found very little significant freezing below the $-38^{\circ} \mathrm{C}$ isotherm despite the presence of ice nuclei. Their findings emphasize the importance of supercooled liquid water in cloud electrification. This process is also sensitive to aerosol content. Khain et al. (2005) employed a cloud model that included detailed microphysics, cloud condensation nuclei, and ice nuclei. Their findings suggest that aerosol-rich clouds exhibit enhanced convection, leading to a more developed vertical structure and to thunderstorms. Furthermore, polluted urban centers often exhibit excess lightning (Orville et al. 2001; Pinto et al. 2013), and aerosol content may increase in developing regions in the coming decades.

Cloud characteristics are commonly used as predictors/ proxies for flash rate. Perhaps the most widely used proxy is the maximum cloud-top height to the fifth power times a constant (Williams 1985; Michalon et al. 1999; Yoshida et al. 2009; Banerjee et al. 2014; Krause et al. 2014; Romps et al. 2014). Cloud-base height (Williams and Stanfill 2002; Williams et al. 2005), ice mass flux (Blyth et al. 2001; Deierling et al. 2008; Lynn and Yair
2010; Yair et al. 2010; Finney et al. 2018), and precipitation (Romps et al. 2014) have also been employed.

Predictions of lightning's sensitivity to climate change vary widely for different regions and studies. Research of the past 100 years found upward trends in the number of thunder days in the western two-thirds of the United States (Changnon and Changnon 2001), as well as in two Brazilian cities (Pinto et al. 2013). Williams et al. (2019) found that during hiatuses in global warming, regional thunder-day records decreased with time along with temperature from 1940 to 1972, and monthly lightning counts from space were statistically flat with time, and therefore mutually consistent with temperature changes from 2000 to 2013. Many studies use surface temperature as a proxy for climate change, with studies of past (Williams 1992; Williams et al. 1999) and future flash rates (Price and Rind 1994; Michalon et al. 1999; Trapp et al. 2007, 2009; Romps et al. 2014; Seeley and Romps 2015) ranging from a $6 \%-100 \%$ increase in response to a rise of $1^{\circ} \mathrm{C}$ to a $15 \%$ decrease by the year 2100 with $\sim 5^{\circ} \mathrm{C}$ of warming (Finney et al. 2018). Romps et al. (2014) estimated a $12.5 \%$ increase in cloud-to-ground (CG) strikes in the continental United States per $1^{\circ} \mathrm{C}$ rise in global surface temperature. Under a doubled $\mathrm{CO}_{2}$ scenario, Price and Rind (1994) predicted a global rise of $5 \%$ per $1{ }^{\circ} \mathrm{C}$ of surface warming 35 years in the future. Under the same scenario, Michalon et al. (1999) predicted a rise of $10 \%$ in global flash rate per $2^{\circ} \mathrm{C}$ of surface warming. Many of these findings are of the same order as the Clausius-Clapeyron water vapor sensitivity to temperature (saturation vapor pressure increases approximately $7 \%$ per $1^{\circ} \mathrm{C}$ of warming). These studies use dynamic approaches, and do not include modeling of microphysical processes or ice flux. Finney et al. (2018) used a model that incorporated ice physics and featured a decrease in the depth of the charging zone in storm clouds due to increased temperatures to compare two parameterizations. Using upward cloud ice flux, their model produced profoundly different results from those it produced using the cloud-top-height parameterization. In a model run from the present day to the year 2100 under a strong global warming scenario, the former produced a $28.3 \%$ decrease while the latter gave a $30.3 \%$ increase in flash rate over the tropics.

Despite their often highly detailed descriptions, there is a disadvantage to using cloud and precipitation parameters as proxies for large-scale predictions. There is evidence suggesting that climate models overestimate cloud liquid water content (Jiang et al. 2012). In the context of general circulation models (GCMs), convective clouds are a subgrid-scale process, and are therefore represented by parameterizations (Price 2013). The horizontal 
scale of a large thunderstorm is $\sim 25 \mathrm{~km}$ (Seeley and Romps 2015). The grid spacing of high-resolution global GCMs is $50-100 \mathrm{~km}$ (HiRAM, MiROC4H), but the vast majority of these models use pixel sizes of hundreds of kilometers (ECHAM5-MPI, UKTR, HAD-CM3). The current work deals with thunderstorm clusters, and is less concerned with the intensity of charge separation and more with the large-scale drivers leading to thunderstorms, regardless of intensity. Therefore, we focus on large-scale, continuous parameters that are relevant to coarse-grid models. Examples of such variables that have been tied to lightning include vertical temperature gradient (profile) between two levels (Brooks et al. 2003; Ziv et al. 2009; Gijben et al. 2017), wet-bulb temperature and wet-bulb potential temperature (Williams 1992; Williams and Renno 1993), sensible heat flux (Williams and Stanfill 2002), and updraft speed (Baker et al. 1995, 1999; Del Genio et al. 2007; Wang et al. 2017).

Two additional variables that measure instability are lifted index (LI) and convective available potential energy (CAPE). Both are based on parcel theory, which is a significant simplification, given thunderstorms' turbulent mixing. Parcel theory predicts significantly greater updraft speeds than those observed for all but the largest supercell storms (Williams et al. 2005; Williams 2005) However, both LI and CAPE are employed by National Oceanic and Atmospheric Administration (NOAA)'s Storm Prediction Center as indicators of favorable environments for severe thunderstorms. LI and CAPE differ in their vertical structure. LI indicates the instability of a single level, whereas CAPE is an integration over multiple levels. Blanchard (1998) showed that CAPE divided by the level of free convection exhibits a well-correlated relationship with LI.

CAPE has been used in many studies, particularly over the continental United States (Rutledge et al. 1992; Williams et al. 2002; Brooks et al. 2003; Bright et al. 2005; Romps et al. 2014; Seeley and Romps 2015). However, the dynamics governing these thunderstorms differ significantly from the tropics, where CAPE values are similar over land and sea while lightning over land exceeds lightning over sea by an order of magnitude (Lucas et al. 1996; Williams and Stanfill 2002; Christian 2003; Williams et al. 2005). Romps et al. (2018), found that CAPE $\times$ precipitation correctly predicts the distribution of flash-rate densities over land, but it does not predict the pronounced land-ocean contrast in flash-rate density.

In the current work, several large-scale parameters were tested against thunderstorm observations over Africa. All were taken directly from reanalysis and the two most successful predictors were used to construct an empirical model of thunderstorm clusters.

\section{Methodology}

a. Data

\section{1) NCEP-NCAR REANALYSIS-1}

NOAA's National Centers for Environmental Prediction (NCEP) and National Center for Atmospheric Research (NCAR) Reanalysis-1 system (hereinafter simply NCEP) provides a comprehensive coarse-grid model of the atmosphere from 1948 to the present. The system's main module conducts data assimilation from a range of sources. Data over Africa are extremely sparse, and include ship and buoy observations. Land station temperature, wind, and humidity are not assimilated. Some of the earliest datasets incorporated in the region are raobs from 27 stations, beginning in 1948 in Nairobi and North Africa, 1949 in South Africa, and 1953 in the Sahel. Several global datasets also contribute to the African reanalysis, including U.S. Air Force (USAF) TD13 synoptic observations (beginning around 1950) and USAF TD54 global rawinsonde (beginning in 1948) (Jenne 1992; Jenne et al. 1993). By comparison, the ECMWF interim reanalysis (ERAInterim) ingests surface temperature at 6-h intervals; however, currently the dataset begins in 1979 .

The NCEP data are integrated with the NCEP global spectral model, using spectral statistical interpolation (SSI) (Parrish and Derber 1992). The output used here has 17 pressure levels, with a horizontal grid size of $2.5^{\circ}$ $\left(\sim 250 \mathrm{~km}^{2}\right)$ and a time step of $6 \mathrm{~h}$. NCEP calculates the difference between the station elevation and the elevation that is consistent with the reported surface pressure, and the lowest two reported heights, assuming a lapse rate of $-6.5^{\circ} \mathrm{km}^{-1}$. NCEP provides a wide selection of output fields that are classified according to the relative influence of observational data on them: $\mathrm{A}=$ strongly influenced by observations (highly reliable); $\mathrm{B}=$ both observations and the model directly affect the variable; and $\mathrm{C}=$ no relevant observations, the variable is derived solely from the model (vulnerable to modeling errors) (Kalnay et al. 1996). NCEP's historical output is temporally varying in nature due to the inclusion of different datasets from different periods. Poccard et al. (2000) found four abrupt shifts in NCEP's precipitation data (class C) over Africa when compared to an observational dataset, with the most significant shift occurring in 1967. Prior to 1968 very few datasets were integrated into the reanalysis over tropical Africa, and rawinsonde and upper-air data are still scarce in the region (Kalnay et al. 1996; Poccard et al. 2000), suggesting that NCEP's 
reanalysis over Africa may be more susceptible to the GCM's limitations, particularly aloft.

\section{2) WORLD WIDE LIGHTNING LOCATION NETWORK}

The World Wide Lightning Location Network (WWLLN) is a network of 70+ stations unevenly distributed around the globe, run by the University of Washington. It began operating in 2004 with 18 stations and has progressively grown since. WWLLN detects electromagnetic waves generated by individual $\mathrm{CG}$ strokes in the very-low-frequency (VLF; $f_{\mathrm{VLF}}=3-30 \mathrm{kHz}$ ) band. Stations measure the time of group arrival of the radiation, and an optimal position for the discharge is calculated based on measurements from at least five stations that surround it (Rodger et al. 2006; Virts et al. 2013). As of 2013, the network's detection efficiency was estimated at $30 \%$ for CG strokes of $30 \mathrm{kA}$ or greater (Mezuman et al. 2014; Holzworth 2017) A typical CG return stroke has a magnitude of approximately $19.5 \mathrm{kA}$ (Cummins and Murphy 2009). As such, WWLLN like other lightning location networks, does not capture all individual strokes. WWLLN detections are strongly biased toward lightning with higher peak currents (Abarca et al. 2010). The addition of more stations has improved the network's ability to detect weaker strokes (Rodger et al. 2006; Rodger 2008; Hutchins et al. 2012) and has improved the quality of data over Africa. WWLLN's detection efficiency is approximately 3 times higher over sea than over land (Rudlosky and Shea 2013). Several studies have assessed WWLLN's abilities through comparisons to local ground-based networks (Abarca et al. 2010; Abreu et al. 2010) and the TRMM Lightning Imaging Sensor (LIS) (Rudlosky and Shea 2013) and shown that spatiotemporal distributions of thunderstorms can be reproduced successfully. VLF wave attenuation and the minimum detectable energy (MDE) of a particular region/station depends on ionospheric and surface conditions. The relative detection efficiency and MDE of the network is lower in southeast Africa compared to most other regions (Hutchins et al. 2012). Clustering was employed to mediate this issue.

\section{b. Thunderstorm clusters and preprocessing}

Clustering is commonly used for assessing storm behavior and scale from individual strokes/flashes [as shown by the Optical Transient Detector (OTD) and LIS]. Mezuman et al.'s (2014) clustering algorithm was shown to successfully reproduce the spatiotemporal distribution of global thunderstorm cells. The current work utilized this algorithm to represent thunderstorm parameters, with the understanding that not all clusters are captured. The typical lifetime of a thunderstorm is 30-60 min (Latham 1981). To capture smaller storms, the algorithm translates the raw WWLLN coordinates and arrival times into clusters on a $0.15^{\circ}(\sim 15 \mathrm{~km})$ grid. A cluster is defined as a cell in which at least one stroke has been detected per hour. Adjacent cells (top-bottom, left-right) in which strokes are detected within the same hour are combined into larger clusters. Given WWLLN's limited and increasing detection efficiency, the use of thunderstorm clusters enables the estimation of the global distribution of thunderstorms, rather than an accurate quantification of the number of storms.

To create a cluster dataset that matches NCEP's resolution, the NCEP data were interpolated to a $2.4^{\circ}$ grid and hourly clusters were integrated over a whole day (0000-2300 UTC). Prior to interpolation, there was a small area without overlap in the east-west direction; however, the region of interest (ROI) was defined so that it is covered completely. The clusters were counted for each NCEP pixel to produce two parameters: cluster number and cluster area (Fig. 1). The final units for cluster number are defined as the number of clusters per day in a standardized $1^{\circ} \times 1^{\circ}$ box. Cluster area is defined as a daily mean percentage of area covered by clusters, per hour.

\section{c. Early model development}

The African region is defined as $30^{\circ} \mathrm{N}-30^{\circ} \mathrm{S}, 19.2^{\circ} \mathrm{W}-$ $52.8^{\circ} \mathrm{E}$. To estimate the average number and area of clusters during a given day in the ROI, the daily geographic means of the cluster parameters and several NCEP fields were compared for one full year, 2013. Lightning data were integrated to a daily value, or taken from late afternoon to evening hours when thunderstorm activity peaks (Price 1993; Williams et al. 2000), taking into account that the African region spans five time zones. Fields tested included LI, temperature profiles, surface temperature, temperature anomaly (temperature minus monthly mean temperature), specific humidity at $1000 \mathrm{hPa}$, and vertical velocity at $500 \mathrm{hPa}$ (omega) (Table 1). The initial analysis did not produce good correlations with omega, possibly due to inaccuracies of NCEP upper-level data over Africa (Poccard et al. 2000). Despite temperature's A classification, temperature profiles had weaker correlations with cluster variables compared to the top performers. Several of the tested variables have been shown to have a significant relationship with CAPE: omega (Brooks 2013), specific humidity (Trapp et al. 2007, 2009; Seeley and Romps 2015), and LI (Blanchard 1998).

Two significant large-scale parameters correlated strongly and consistently with both cluster parameters: specific humidity $(q)\left(\mathrm{g} \mathrm{kg}^{-1}\right)$, with a correlation of 0.779 , and LI $(\mathrm{K})$ with a negative correlation of -0.795 . We chose to focus solely on these two variables. Both are classified B in the NCEP reanalysis (Kalnay et al. 1996). 


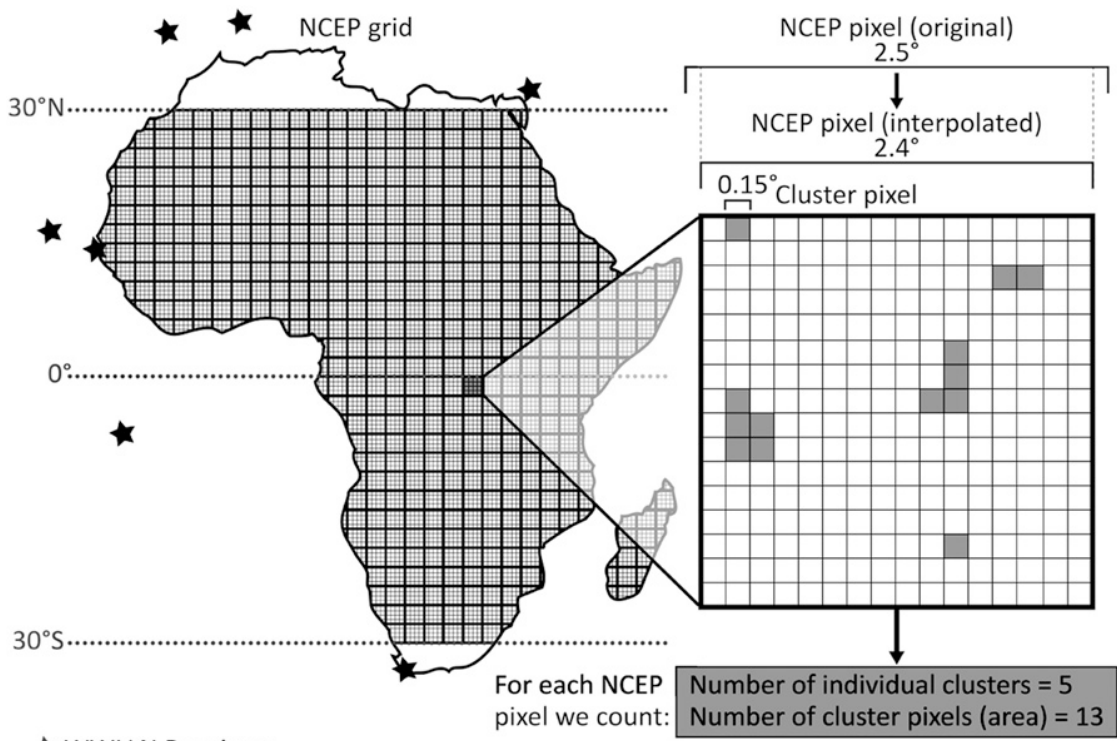

\section{WWLLN Receivers}

FIG. 1. Illustrated comparison of the grid size of the datasets, with the WWLLN receivers in the region (stars). NCEP's $2.5^{\circ}$ grid is interpolated to a $2.4^{\circ}$ grid to accommodate the clusters' $0.15^{\circ}$ grid (shown at right). Cluster number and area are calculated for the $2.4^{\circ}$ grid.

Lifted index is a measure of buoyancy, defined as

$$
\mathrm{LI}=T_{\text {env }}-T_{\text {parcel }},
$$

where $T_{\text {env }}$ is the ambient temperature at $500 \mathrm{hPa}$, and $T_{\text {parcel }}$ is defined by taking a parcel from near-surface level (NCEP uses 995 sigma levels) and simulating its rise through the troposphere to $500 \mathrm{hPa}$ (dry adiabatic until condensation, then moist adiabatic) (Blanchard 1998). LI correlates negatively with lightning, as its negative values indicate conditions favorable to convection: the parcel will rise as it is warmer and less dense than its environment. The current work employs LI due to its consistent correlations with clusters in the testing phase and its standard two-dimensional definition. While CAPE is sensitive to the choice of air parcel (Williams and Renno 1993; Emanuel 1994; Blanchard 1998; Craven et al. 2002), LI is produced directly by NCEP as an output field, freeing it from the assumptions of the researcher. NCEP offers two types of LI: surface level and best-four-layer LI. Both yielded similar correlations in the early analysis. Gijben et al. (2017) tested both "best LI" and surface LI in the construction of their lightning index, and found that surface LI was more successful. Surface LI was employed here, taken as a daily mean.

Specific humidity $q$ is the water content of an air parcel expressed in terms of grams of water vapor per $1-\mathrm{kg}$ air parcel. The field was taken as a daily mean at $1000 \mathrm{hPa}$ and correlated positively with cluster parameters. Examples of NCEP output of LI and $q$, and raw cluster density from WWLLN, can be seen in Fig. 2. It is worth noting that LI and $q$ are not independent; they correlate negatively with each other in the ROI, with $r=-0.85651$. However, they represent substantially different "ingredients" necessary for thunderstorm formation, as deep moist convection requires a conditionally unstable environmental lapse rate, and sufficient moisture in the rising parcel, enabling it to reach a level of free convection (Doswell et al. 1996).

Geographic means do not address the spatial distribution of storms, and comparisons between the NCEP

TABLE 1. Correlation coefficients for daily geographic means over the ROI. The $p$ value, the probability of finding these, or more extreme, results when the null hypothesis is true, was calculated and found to be $p \leq 0.00001$ for all tests.

\begin{tabular}{lccc}
\hline \hline & Cluster number at 2000 UTC & Cluster area at 2000 UTC & Classification \\
\hline Lifted index: $T_{500}-T_{\text {parcel }}$ & -0.79506 & -0.8121 & B \\
$\Delta$ Temperature: $T_{1000}-T_{850}$ & 0.6937 & 0.65136 & A (temperature) \\
$\Delta$ Temperature: $T_{850}-T_{500}$ & 0.56237 & 0.65386 & A (temperature) \\
Specific humidity & 0.77953 & 0.7218 & B \\
Omega, $500 \mathrm{hPa}$ & -0.56174 & -0.43212 & B \\
\hline
\end{tabular}



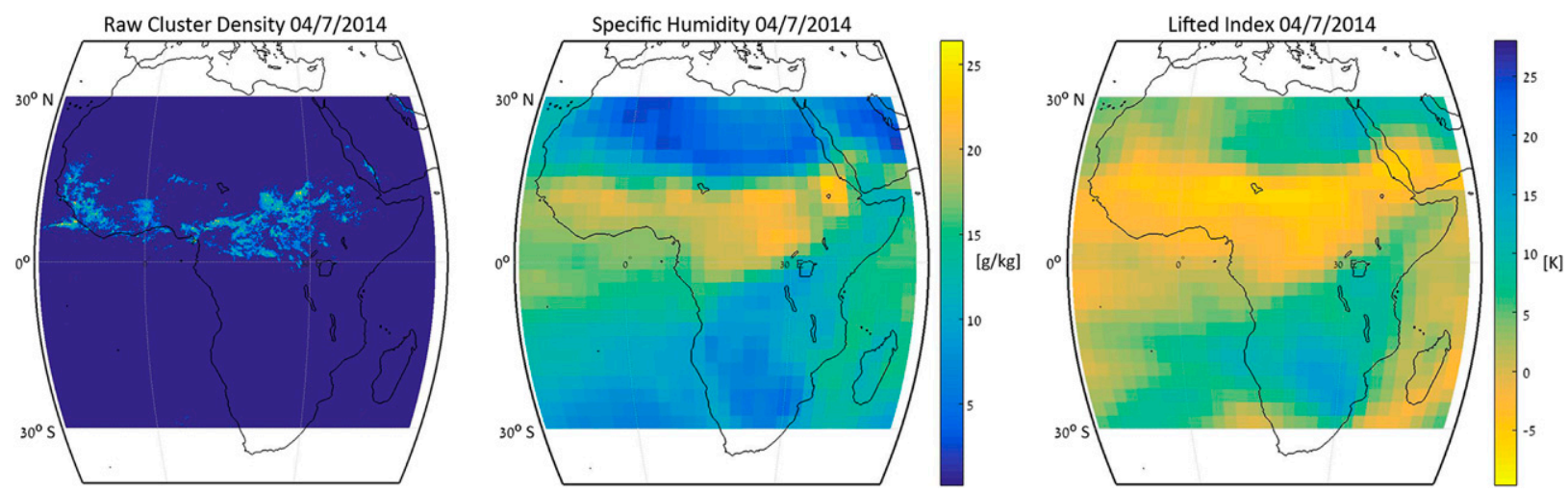

FIG. 2. Example of daily data from 4 Jul 2014: (left) raw cluster density from WWLLN, (center) daily mean specific humidity at $1000 \mathrm{hPa}$ from NCEP, and (right) daily mean surface LI with reversed color scale from NCEP.

variables and the cluster parameters on a pixel-by-pixel basis revealed nonlinear associations, which can be seen in Fig. 3. When three variables were compared together, the distribution functions of LI, $q$, and cluster number and area showed a clear shape with a concentrated region of high cluster values over minimum values of $\mathrm{LI}$ and maximum values of $q$, and very few outliers. This distribution (Fig. 3) from 2013 was used to construct an empirical model to predict the number and area of thunderstorm clusters.

\section{d. The empirical model}

The empirical model (EM) is based on 1 year of daily mean LI and $q$, as well as WWLLN-derived clusters in the ROI. This distribution comprises $26 \times 31$ pixels $\times$ 365 days $=294190$ data points. The EM receives input of daily LI and $q$ for the desired year. It then produces a prediction of cluster number and area on any given day, based on the data in Fig. 3. The EM includes two separate predictive schemes. Both treat land and sea separately, so that pixels over land are predicted based on the distribution of continental pixels, and likewise for pixels over sea. Daily predictions are used to calculate monthly mean predictions.

The observations of cluster number and area from the reference year (2013) are binned according to their LI and $q$ values. For any given combination of LI and $q$, there are two matching arrays of cluster observations: $Z_{\text {number }}\{\cdots\}$ and $Z_{\text {area }}\{\cdots\}$. These are used to construct two prediction schemes.

\section{1) THE MEAN PREDICTION SCHEME}

The mean scheme (MS) calculates a mean daily value of the cluster observations $\left\langle Z_{\text {number }}\right\rangle$ and $\left\langle Z_{\text {area }}\right\rangle$ for each particular LI and $q$ set in the reference year. Figure 4 shows the mean values of the data in Fig. 3. These values
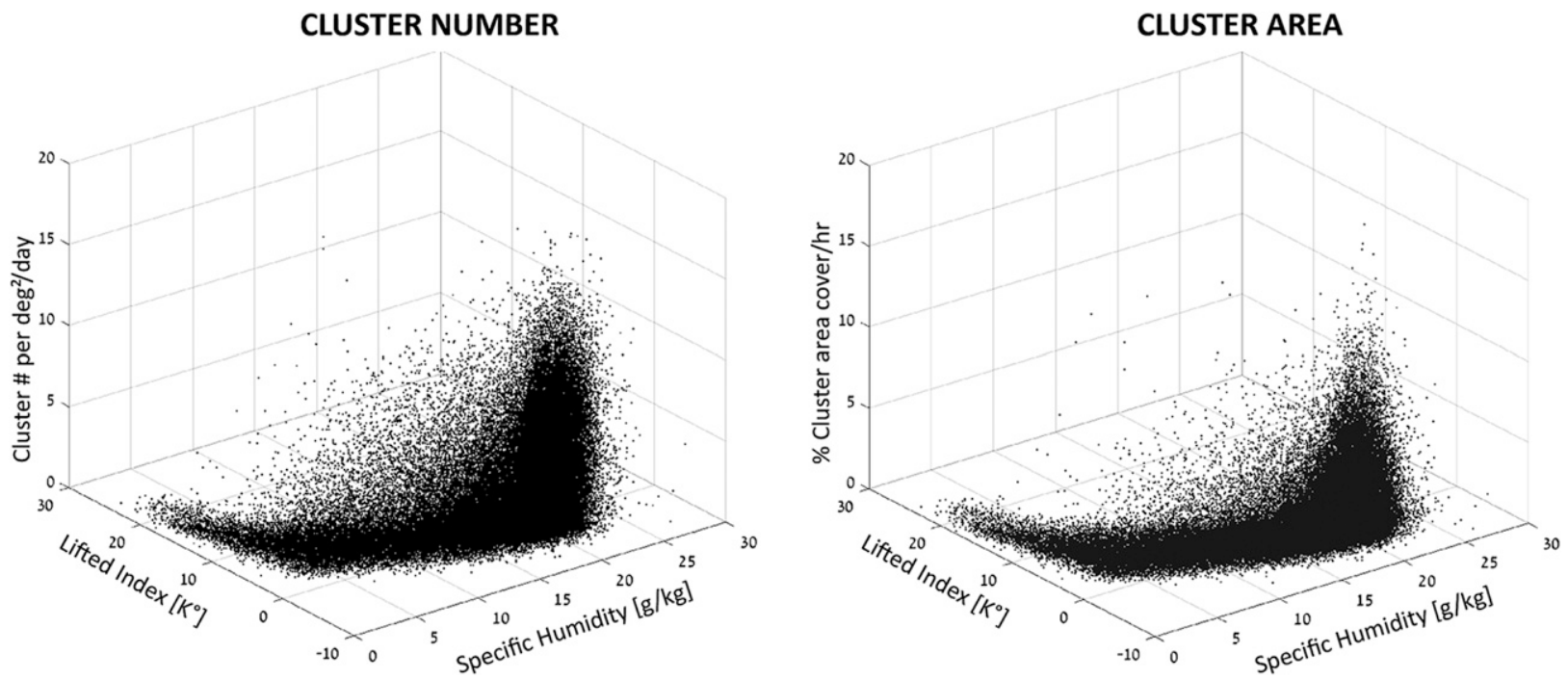

FIG. 3. Distribution functions of cluster number and area, LI, and $q$ for 2013. Each dot is a daily value of one $2.4^{\circ}$ pixel. The $x$ axes are LI, and the $y$ axes are specific humidity. The $z$ axes are (left) cluster number and (right) cluster area. All data are for continental pixels that contain at least one cluster per day. 
MEAN CLUSTER NUMBER

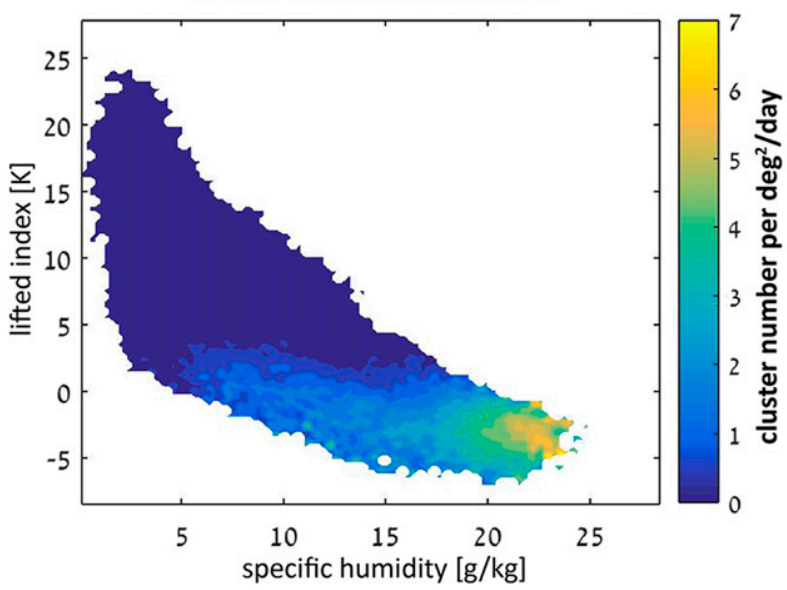

MEAN CLUSTER AREA

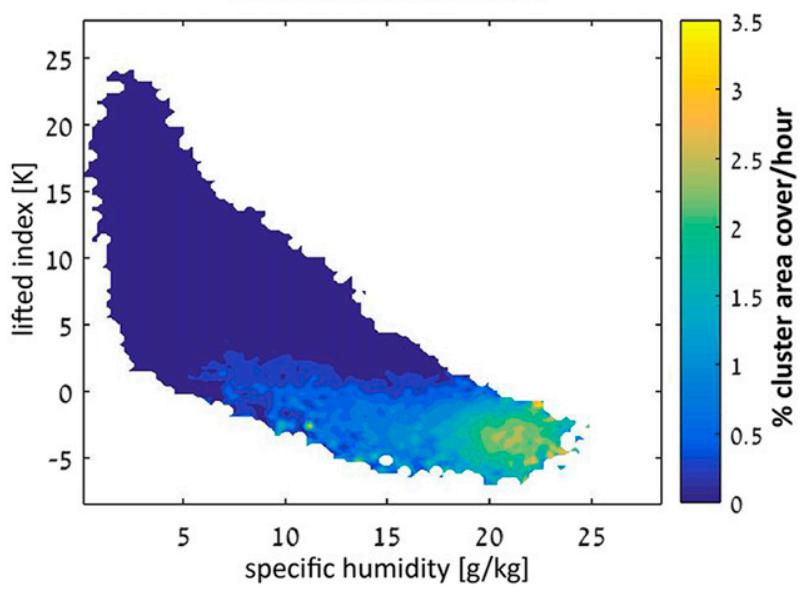

FIG. 4. Reference grids of mean prediction scheme for (left) cluster number and (right) area over land based on the distributions in Fig. 3: mean values are calculated from the distributions of observed cluster values for every existing combination of lifted index and specific humidity in 2013. Similar grids are produced for pixels over sea.

are used as the reference for the prediction (see the online supplemental material). Missing values are interpolated from surrounding locations. The algorithm runs on the NCEP data in the prediction year, checks each pixel's LI and $q$ values, and inserts the mean daily cluster values from the reference. Thunderstorms are not a continuous phenomenon. In contrast, the MS is continuous in its design. When predicting daily clusters, the maps exhibit low variability between pixels, unlike real storm data. The MS improves significantly when it is aggregated to a monthly mean, as the clusters reduce in spatial variability when aggregated, enabling the MS to better represent thunderstorm distributions on a monthly time scale (Fig. 5). Maximum values of cluster area correspond to LI values of $\sim-4 \mathrm{~K}$, and $q$ values of 20 $23 \mathrm{~g} \mathrm{~kg}^{-1}$. These values are substantially greater than the climatology for specific humidity for Africa, which has contours of $18 \mathrm{~g} \mathrm{~kg}^{-1}$ with values going to $19 \mathrm{~g} \mathrm{~kg}^{-1}$ within it (Newell et al. 1974). When $q$ rises above $23 \mathrm{~g} \mathrm{~kg}^{-1}$ we see a slight reduction in mean cluster area. Studies by McCaul and Cohen (2002) and Williams et al. (2005) suggest that convective bubbles with broader diameters develop with less surface moisture, and produce higher flash rates and less precipitation. This relationship requires further investigation; however, in the current work the dip in cluster area (Fig. 4, right) occurs for very large clusters, where $q>23 \mathrm{~g} \mathrm{~kg}^{-1}$. In comparison, the cluster number relationship (Fig. 4, left) is slightly more linear with values rising continuously along the $q$ axis, and maximum cluster number values corresponding to maximum $q$ values.

\section{2) THE RANDOM SELECTOR PREDICTION SCHEME}

The random selector (RS) uses NCEP data for any predicted year, and the distributions of observed values
$Z_{\text {number }}$ and $Z_{\text {area }}$ from the matching LI and $q$ combination in the reference year. The scheme randomly selects one observation from $Z_{\text {number }}$ and $Z_{\text {area }}$ for the daily prediction. For example, for a particular LI and $q$ set we have $n$ observations in the reference year. An index between 1 and $n$ is randomly generated using MATLAB's datasample function, and the corresponding number and area values are selected (see codes in the supplemental material). Furthermore, the cluster number and area are coupled. The selected set of cluster values is inserted into the prediction. If a particular LI and $q$ set has no observations in the reference year, predicted cluster values are set to zero:

$$
\begin{aligned}
Z_{\text {number }} & =\{0,2,0,0,0,1,0,1\} \\
Z_{\text {area }} & =\{0,5,0,0,0,3,0,1\}
\end{aligned}
$$

In the example, units for $Z_{\text {number }}$ are the number of individual clusters in one $2.4^{\circ}$ pixel. Units for $Z_{\text {area }}$ are the number of cluster pixels within one $2.4^{\circ}$ pixel.

Unlike the MS, where two pixels with the same set of LI and $q$ values will be assigned the same prediction, the random selection process occurs for every pixel daily. Therefore, the RS captures more variability and extreme values than the MS. The RS is quite erratic and does not reflect a realistic synoptic weather pattern in daily predictions. It too benefits from aggregation to a monthly mean as it becomes more consistent.

To observe the EM's abilities across both hemispheres, monthly predictions from January and July 2014 are displayed in Fig. 5 and compared with cluster observations derived from WWLLN. The monthly predictions showed similar results to the observations in terms of the boundaries of the active thunderstorm region over land. 


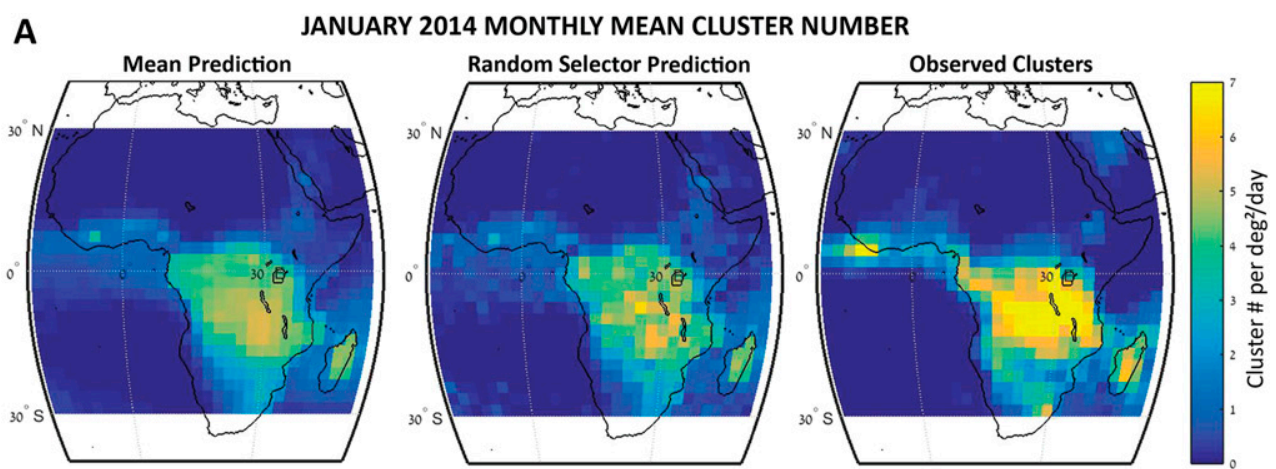

PREDICTION SCHEME ERRORS
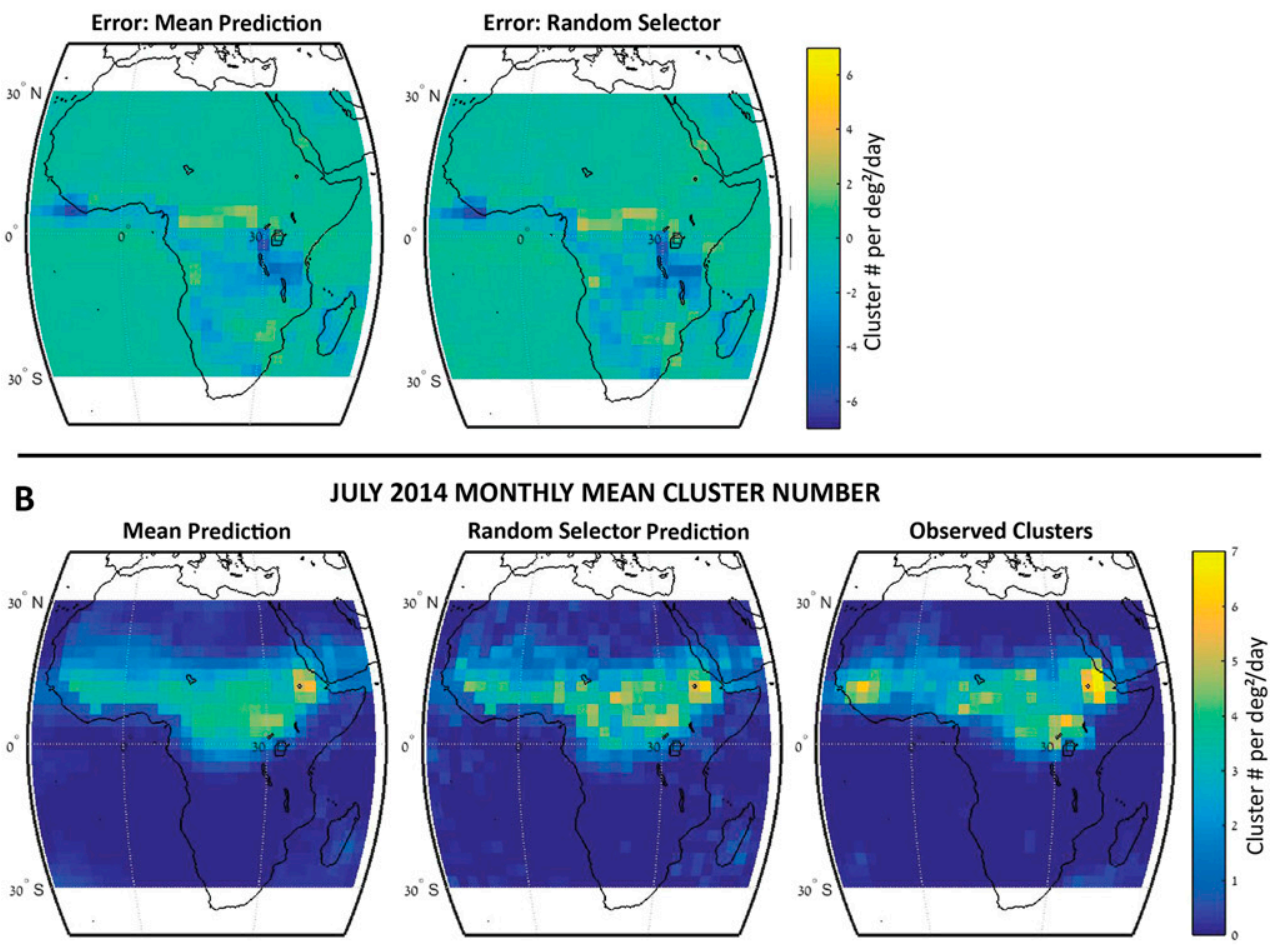

PREDICTION SCHEME ERRORS

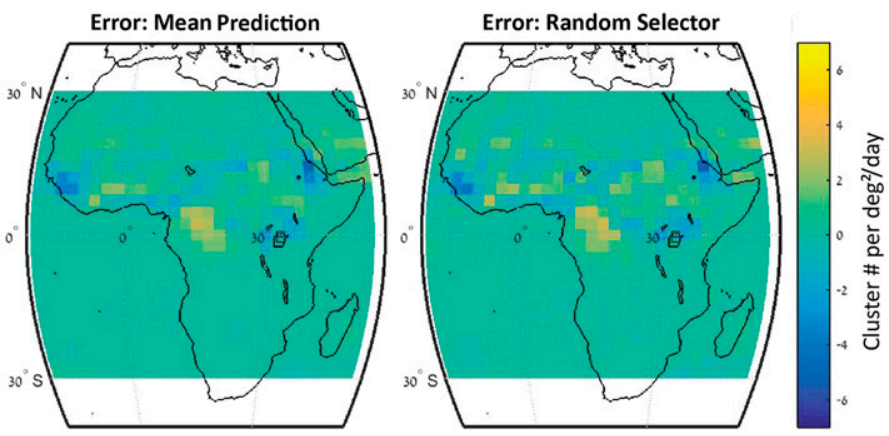

FIG. 5. Comparison of the predictions of monthly mean number of clusters for (a) January 2014 and (b) July 2014, and their errors (prediction minus observations). In (a) and (b), the individual panels show (top left) the results of the mean scheme, (top center) the results of the random selector, (top right) the observed number of clusters from WWLLN, (bottom left) the errors of the mean scheme, and (bottom right) the errors of the random selector. 
Both schemes' January predictions (Fig. 5a) shifted the boundary of the active thunderstorm area slightly northward, causing a thin strip of positive errors above the equator. Despite good spatial agreement with observations, the majority of the maximum region experienced a much higher number of clusters than either of the schemes predicted. On a daily scale, neither of the schemes is able to insert values that are more extreme than those observed in the reference year.

Aggregation to a monthly time scale is beneficial, but not without limitations. It is worth noting that the RS does not provide a basis for extrapolation, whereas the MS could be expanded upon in this way.

Another area with significant errors was around Liberia on the western coast, where both schemes underestimated the number of clusters. Over sea, around the Gulf of Guinea, both schemes slightly overestimated the number of clusters, with two compounding factors contributing to this bias. The first is that WWLLN's detection efficiency is higher over sea (Rudlosky and Shea 2013), while most thunderstorms occur over land. Second, there is a significant hemispheric asymmetry in the ROI in the proportion of land versus sea. Most of the Southern Hemisphere ( $\mathrm{SH})$ portion is over sea, which makes the prediction more vulnerable to errors, particularly in SH summer (January).

The July predictions proved more accurate than those of January for both schemes, with minimal overestimations over sea. However, the Northern Hemisphere $(\mathrm{NH})$ portion is almost entirely continental. The most significant error was the slight westward shift of the southern boundary of the active thunderstorm region, leading to an overestimation in the number of clusters around the Republic of the Congo.

To test the skill of the EM, the monthly predictions of both schemes for 2014 were compared with WWLLN's observations using the normalized root-mean-square error (NRMSE) to determine the relative success of the predictions (Table 2):

$$
\begin{aligned}
\text { RMSE } & =\sqrt{\frac{\sum_{i=1}^{n}\left(y_{\text {forecast }}-y_{\text {observed }}\right)^{2}}{n},} \\
\mathrm{NRMSE} & =\frac{\mathrm{RMSE}}{y_{\max }-y_{\min }} .
\end{aligned}
$$

The random selector was found to be more successful than the mean scheme in predicting both cluster parameters. The best scheme was the RS's prediction of cluster number (RS-CN) with a mean error of $13.5 \%$. The worst was the MS's prediction of cluster area with $20.6 \%$.
TABLE 2. Normalized root-mean-square error of the prediction schemes in predicting monthly values of cluster number and area for 2014.

\begin{tabular}{lcc}
\hline \hline & Cluster number & Cluster area \\
\hline Random selector & 0.13504 & 0.14813 \\
Mean scheme & 0.16264 & 0.20629 \\
\hline
\end{tabular}

\section{Long-term trends}

The empirical model's most successful scheme (RSCN) was run from NCEP's earliest reanalysis in 19482016 to create a simulation of thunderstorm activity over Africa in the past 68 years. This period marks the beginning of a large and steady increase in carbon emissions, both in Africa (Boden et al. 2015a) and worldwide (Boden et al. 2015b). The predictions were aggregated to produce annual geographic means, and were compared with surface temperature in the ROI from NCEPNCAR Reanalysis-1. Animations of annual and decadal means from the model can be viewed in the supplemental material. Annual-mean African surface temperature did not appear to rise significantly between the 1950s and 1980s, consistent with findings from the Intergovernmental Panel on Climate Change (IPCC 2014). The time series, shown in Fig. 6, exhibits a small local maximum in cluster number in 1962-63, with the upward trend to that peak beginning in 1957, and trending downward to a local minimum in 1975, with no corresponding rise in surface temperature. The local maximum in the early 1960 s corresponds to increased elevation in Lake Victoria (Yin and Nicholson 1998) in the same period, and positive anomalies in Congo River discharge and precipitation from NCEP, although it was shown that the NCEP anomaly was overestimated (Poccard et al. 2000). Price and Asfur (2006b) reconstructed lightning activity over Africa from 1950 to 2000, using NCEP values of upper-atmospheric water vapor and their connection to Schumann resonance magnetic field measurements. The trends in the current work are mostly in keeping with their findings, with a discrepancy in the 1970s, where Price and Asfur found a significant minimum. In comparison, the current time series shows a fairly broad and flat minimum from 1975 to 1994, with a transient 1-yr spike in 1979. Another somewhat broader spike in cluster number occurs in 1997-99 before again falling almost back to the broad minimum that begins in 1975. This peak appears to be positively correlated to a similar spike in temperature. There also appears to be a slow rise in thunderstorm number beginning around 1995 and slowly trending upward until 2005, correlating with a similar upward trend in surface temperature. Finally, 


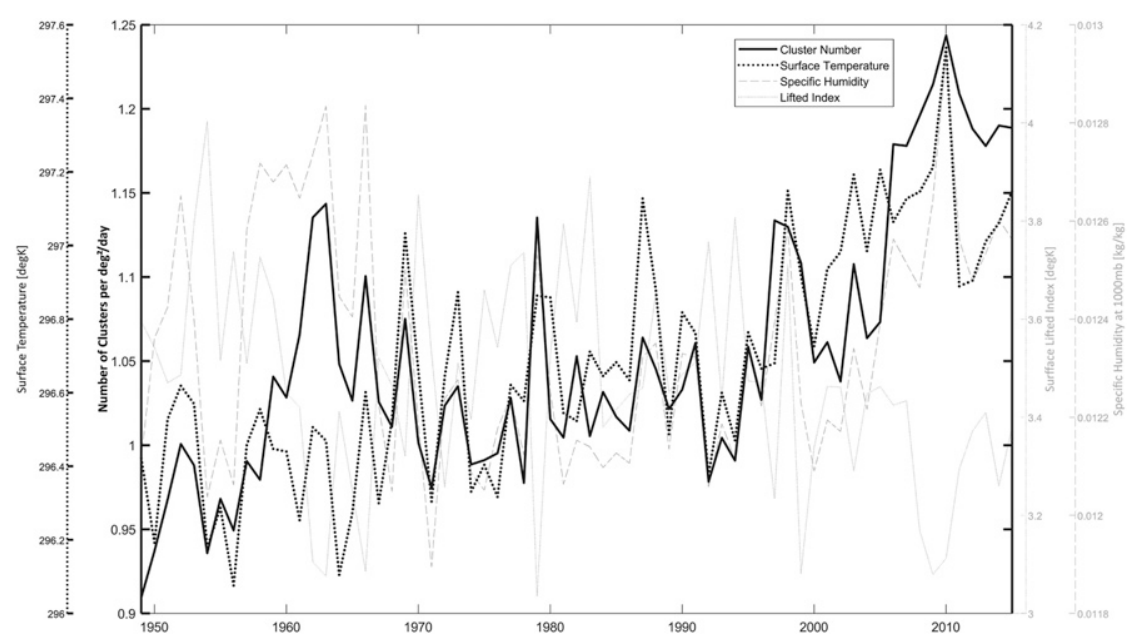

FIG. 6. Annual means for 1948-2016 in the African region: cluster number as calculated by the random selector (solid black), surface temperature (dotted black), LI (gray), and specific humidity (gray dashed). A 2-yr smoothing filter (moving average) was applied.

there is a sharp rise in the number of clusters in 2006 to an unprecedented higher level, and reaching a peak in both cluster number and temperature in 2010 .

To investigate the sensitivity of tropical thunderstorm clusters to warmer environments, a direct comparison was made between annual-mean surface temperature and simulated cluster number and area derived from the RS scheme. In Fig. 7, each data point is a geographic annual mean over the entire ROI. The correlation coefficients were 0.74551 , and 0.74372 for cluster number and area respectively, indicating that a warmer environment explains $\sim 55 \%$ of the interannual variability in simulated thunderstorm clusters. The relationship is highly sensitive, showing a $40 \%$ increase in the number of thunderstorms in response to a rise of $1^{\circ} \mathrm{K}$. This result reflects the enhanced evaporation resulting from higher surface temperatures, which in turn supplies more latent heat for the development of storms.

To compare the spatial distribution of thunderstorms and see how they have changed from the 1950s to the 2000 s, decadal monthly means of cluster number were calculated and mapped (see animations in the supplemental material). January and July were taken as samples and are shown in Fig. 8. In January of the 1950s there were far fewer clusters over the sea in the Gulf of Guinea, compared with the 2000s. In the 2000s the maximum zone in the center of the continent (Congo, Tanzania, Zambia, Mozambique) had significantly higher values, and its area had nearly tripled in the latitudinal direction. In the northeast, over Ethiopia and Sudan, values of cluster number were higher in the 1950s. The northern boundary of thunderstorm activity along western Africa was farther south in the 2000s, consistent with the many droughts that afflicted the Sahel in that decade (Herrmann et al. 2005).

The decadal means in July were fairly similar. The most obvious difference was in the 2000s, when the southern boundary of the area of active thunderstorms over central Africa was farther south than in the 1950s, with storms crossing the equator, reaching $\sim 7^{\circ}$ farther into the SH over the Congo River basin. This region is known to exhibit a strong semiannual cycle of precipitation and lightning (Williams and Sátori 2004). While the spatial pattern was similar, the number of clusters over much of West Africa, particularly the western Sahel, in July was higher in the 2000s than the 1950s,

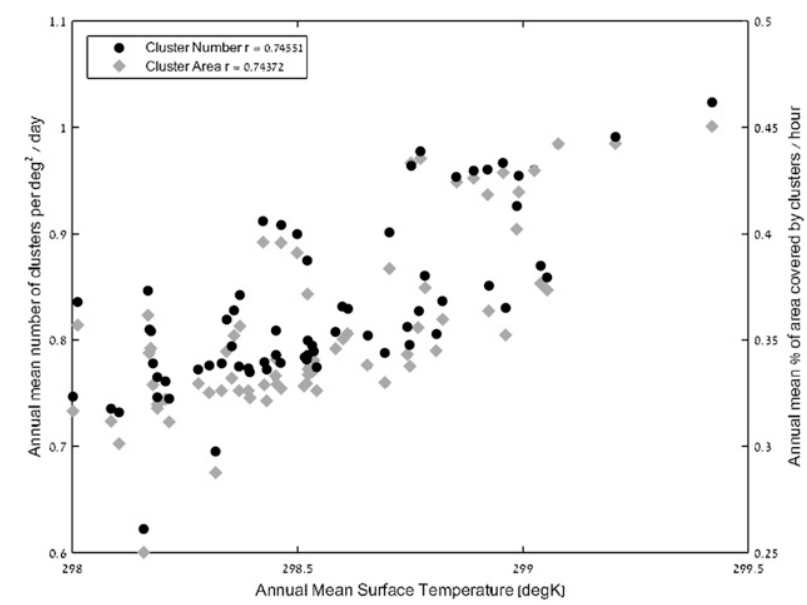

FIG. 7. Sensitivity of simulated thunderstorm clusters to surface temperature. Each dot represents the annual-mean cluster number (black dot) and area (gray diamond) from 1948 to 2016, calculated by the RS scheme. 
DECADAL MEAN NUMBER OF CLUSTERS: JANUARY
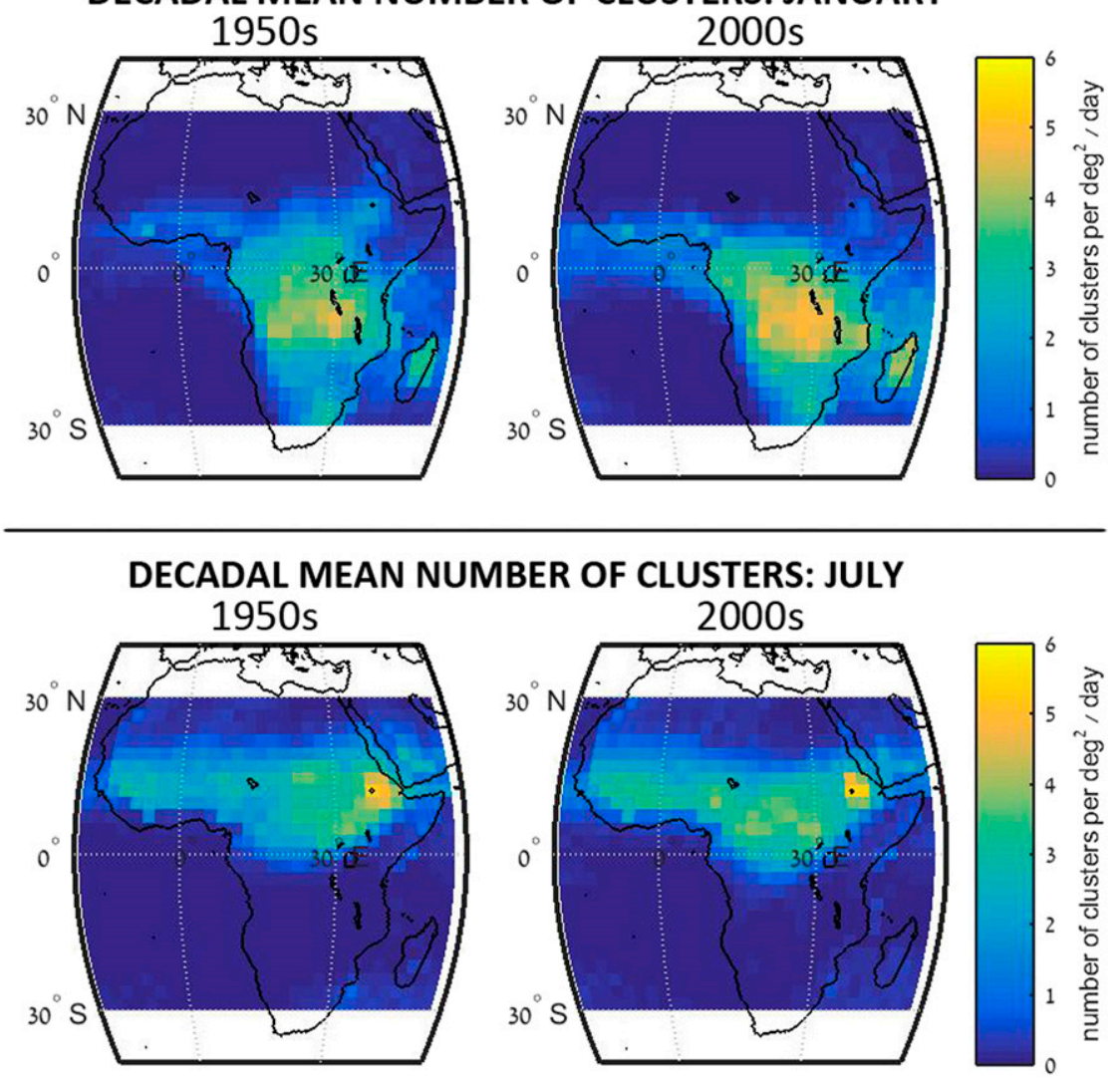

FIG. 8. Decadal-mean number of simulated thunderstorm clusters in the (left) 1950s and (right) 2000s for (top) January and (bottom) July.

indicating that wet seasons in the 2000s may have been characterized by more intense thunderstorms than the 1950s. This may reflect Taylor et al.'s (2017) finding that the frequency of severe MCSs in the Sahel has tripled over the past 35 years (see April and October maps in the supplemental material). Several regions showed slightly lower cluster values in the July maps of the 2000s compared to the 1950s. These findings are in keeping with broad trends in precipitation in several regions: in Libya and Saudi Arabia Donat et al. (2014) found decreases in the total amount of precipitation and the number of heavy precipitation days between 1960 and 2010. In southern Africa, Nicholson (2000) found positive annual rainfall anomalies in most of the 1950s. In the Sudan, Rowell et al. (1995) found a rainfall anomaly of $\sim-1.5 \%$ from July to September beginning in the mid-1960s and continuing through the 1990s, on a decadal (low frequency) time scale.

Between the 1950s and the 2000s, EM results in the Horn of Africa (Somalia) exhibit a difference in the intensity of its seasonal cycle. In the 1950s the region showed a strong seasonal cycle with intense thunderstorm activity in July and minimal activity in January. By comparison, in the 2000s, the area experienced more thunderstorm clusters in January, and less in July. This is likely due to the strong influence of El Niño-Southern Oscillation (ENSO) on the interannual variability of precipitation in East Africa, causing intense rains from October to January and reduced precipitation in the Congo (Anyah and Semazzi 2006) (results for April and October can be viewed in the online supplemental material). In the 1950s there was only one El Niño event, compared with three in the 2000s (NOAA 2017).

\section{Discussion and conclusions}

The presented empirical model of thunderstorm number and area uses large-scale parameters to construct a reanalysis-based prediction tool. This tool is not dependent on cloud parameterizations that are often used to construct lightning proxies. This approach can be applied to coarse-grid models and reanalyses without the use of a second parameterization. The random selector scheme was the most successful predictor of thunderstorm 
activity, and was able to predict cluster number and area with considerable skill on a monthly scale. LI and $q$ are both indirectly related to surface temperature, and the results of the empirical model exhibited pronounced sensitivity to surface temperature in the ROI. A direct comparison between annual mean surface temperature and simulated cluster number and area revealed a $40 \%$ increase in the number of thunderstorm clusters in response to a rise of $1 \mathrm{~K}$, and correlation coefficients of 0.74551 and 0.74372 for cluster number and area, respectively. The long-term time series, shown in Fig. 6, exhibited local spikes in the number of clusters with no corresponding rise in surface temperature until the 1990s. Between 1995 and 2005 there was an upward trend in both cluster number and surface temperature, which then transitioned to a sharp rise from 2006 on, reaching an unprecedented higher level, and peaking in 2010 .

The sensitivity presented in the current work refers to the number and area of thunderstorm clusters rather than to flash density. Although clearly related, these variables cannot be compared to each other directly. Cluster number indicates the frequency of storms, but says little about each storm's severity or flash rate. The cluster-area parameter may be a better indicator for storm severity, though this requires further investigation. Louf et al. (2019) found that low values of CAPE correspond to large numbers of small convective cells while high values correspond to small numbers of large convective cells with high updraft speeds. Williams et al. (2005) found that larger convective bubbles lead to larger thunderstorms with higher flash-rate density. Under a doubled- $\mathrm{CO}_{2}$ scenario, Price and Rind (1994) predicted an increase of $\sim 100 \%$ in flash rate over Africa and a $\sim 4^{\circ} \mathrm{C}$ increase in surface temperature. If we were to assume that the flash rate and the number/area of storms are closely related, then the sensitivity found in the current work is more extreme than these findings. However, this comparison is somewhat vague, as it is based on an assumption that these variables scale consistently with each other. Furthermore, the sensitivity to surface temperature as a proxy for climate change does not account for other possible important coincident changes, such as increasing aerosol, that might result in this relationship occurring, even if temperature had no impact on lightning. A significant example of this is climate change leading to an adjustment of the entire vertical temperature profile of the tropical atmosphere, substantially impacting lightning regimes. Looking forward, effort should be made to improve upon the modeling of aerosols and cloud microphysics in GCMs, as the tension between these mechanisms and the dynamic approach used here cause subtle but important changes, which make predictions more challenging.

The primary goal of this study is to present an empirical approach to thunderstorm modeling that can be applied on a regional scale. Constructing a more complete estimation of past thunderstorm activity can be helpful in understanding the long-term behavior of lightning regimes. Future work testing the proposed empirical model using inputs from alternative reanalyses will help determine this method's robustness.

On a more general note, the empirical model presented here is a coarse method that may be applicable for rare-event prediction in other fields/scenarios. The majority of pixels in the analysis exhibit zero clusters per day, and this is the scale at which predictions are made prior to aggregation. This approach may be relevant to research problems where data are lacking in resolution and/or available variables. In addition, the random-selector method has the potential to employ variables whose correlation is not necessarily linear, as it takes values directly from observations, and does not require a functional representation of the relationship between variables. This method could be applied to other events that occur sporadically, such as floods, and may merit further investigation into its use in other fields.

Acknowledgments. Thanks to the NOAA/OAR/ESRL PSD for providing the NCEP-NCAR reanalysis data online, and to the World Wide Lightning Location Network (http://wwlln.net), a collaboration of over 50 universities and institutions, for providing the lightning data used in this work. Special thanks to Keren Mezuman, whose previous works and familiarity with the materials were especially helpful in the early stages of this research.

\section{REFERENCES}

Abarca, S. F., K. L. Corbosiero, and T. J. Galarneau, 2010: An evaluation of the Worldwide Lightning Location Network (WWLLN) using the National Lightning Detection Network (NLDN) as ground truth. J. Geophys. Res., 115, D18206, https://doi.org/10.1029/2009JD013411.

Abreu, D., D. Chandan, R. H. Holzworth, and K. Strong, 2010: A performance assessment of the World Wide Lightning Location Network (WWLLN) via comparison with the Canadian Lightning Detection Network (CLDN). Atmos. Meas. Tech., 3, 1143-1153, https://doi.org/10.5194/amt-31143-2010.

Albrecht, R. G. I., S. J. Goodman, D. E. Buechler, R. J. Blakeslee, and H. J. Christian, 2016: Where are the lightning hotspots on earth? Bull. Amer. Meteor. Soc., 97, 2051-2068, https://doi.org/ 10.1175/BAMS-D-14-00193.1.

Anyah, R. O., and F. H. M. Semazzi, 2006: Climate variability over the greater Horn of Africa based on NCAR AGCM ensemble. 
Theor. Appl. Climatol., 86, 39-62, https://doi.org/10.1007/ s00704-005-0203-7.

Baker, M. B., H. J. Christian, and J. Latham, 1995: A computational study of the relationships linking lightning frequency and other thundercloud parameters. Quart. J. Roy. Meteor. Soc., 121, 1525-1548, https://doi.org/ 10.1002/qj.49712152703.

, A. M. Blyth, H. J. Christian, J. Latham, K. L. Miller, and A. M. Gadian, 1999: Relationships between lightning activity and various thundercloud parameters: Satellite and modelling studies. Atmos. Res., 51, 221-236, https://doi.org/10.1016/ S0169-8095(99)00009-5.

Banerjee, A., A. T. Archibald, A. C. Maycock, P. Telford, N. L. Abraham, X. Yang, P. Braesicke, and J. A. Pyle, 2014: Lightning NOx, a key chemistry-climate interaction: Impacts of future climate change and consequences for tropospheric oxidising capacity. Atmos. Chem. Phys., 14, 9871-9881, https:// doi.org/10.5194/acp-14-9871-2014.

Blanchard, D. O., 1998: Assessing the vertical distribution of convective available potential energy. Wea. Forecasting, 13, 870-877, https://doi.org/10.1175/1520-0434(1998)013<0870: ATVDOC $>2.0 . \mathrm{CO} ; 2$.

Blyth, A., Christian, H. J., K. Driscoll, A. Gadian, and J. Latham, 2001: Determination of ice precipitation rates and thunderstorm anvil ice contents from satellite observations of lightning. Atmos. Res., 59-60, 217-229, https://doi.org/10.1016/ S0169-8095(01)00117-X.

Boden, T. A., G. Marland, and R. J. Andres, 2015a: African FossilFuel $\mathrm{CO}_{2}$ Emissions. Carbon Dioxide Information Analysis Center, accessed 7 February 2020, https://cdiac.ess-dive.lbl.gov/ trends/emis/afr.html.

$\longrightarrow,-$, and 2 2015b: Global Fossil-Fuel Carbon Emissions. Carbon Dioxide Information Analysis Center, accessed 7 February 2020, https://cdiac.ess-dive.lbl.gov/trends/emis/glo_ 2010.html.

Bond, D. W., S. Steiger, R. Zhang, X. Tie, and R. E. Orville, 2002: The importance of $\mathrm{NO}_{x}$ production by lightning in the tropics. Atmos. Environ., 36, 1509-1519, https://doi.org/ 10.1016/S1352-2310(01)00553-2.

Bright, D. R., M. S. Wandishin, R. Jewell, and S. J. Weiss, 2005: A physically based parameter for lightning prediction and its calibration in ensemble forecasts. Conf. on Meteorological Applications of Lightning Data, San Diego, CA, Amer. Meteor. Soc., 4.3, https://ams.confex.com/ams/Annual2005/ techprogram/paper_84173.htm.

Brooks, H., 2013: Severe thunderstorms and climate change. Atmos. Res., 123,129-138, http://dx.doi.org/10.1016/j.atmosres.2012.04.002.

- J. Lee, and J. Craven, 2003: The spatial distribution of severe thunderstorm and tornado environments from global reanalysis data. Atmos. Res., 67-68, 73-94, https://doi.org/ 10.1016/S0169-8095(03)00045-0.

Changnon, S. A., and D. Changnon, 2001: Long-term fluctuations in thunderstorm activity in the United States. Climatic Change, 50, 489-503, https://doi.org/10.1023/A:1010651512934.

Christian, H. J., 2003: Global frequency and distribution of lightning as observed from space by the Optical Transient Detector. J. Geophys. Res., 108, 4005, https://doi.org/ 10.1029/2002JD002347.

Cooray, V., C. Cooray, and C. J. Andrews, 2007: Lightning caused injuries in humans. J. Electrost., 65, 386-394, https://doi.org/ 10.1016/j.elstat.2006.09.016

Craven, J., R. Jewell, and H. Brooks, 2002: Comparison between observed convective cloud-base heights and lifting conden- sation level for two different lifted parcels. Wea. Forecasting, 17, 885-890, https://doi.org/10.1175/1520-0434(2002) $017<0885: \mathrm{CBOCCB}>2.0 . \mathrm{CO} ; 2$.

Cummins, K. L., and M. J. Murphy, 2009: An overview of lightning locating systems: History, techniques, and uses, with an in-depth look at the U. S. NLDN. IEEE Trans. Electromagn. Compat., 51, 499-518, https://doi.org/10.1109/TEMC.2009.2023450.

Deierling, W., W. A. Petersen, J. Latham, S. Ellis, and H. J. Christian, 2008: The relationship between lightning activity and ice fluxes in thunderstorms. J. Geophys. Res., 113, D15210, https://doi.org/10.1029/2007JD009700.

Del Genio, A. D., M. S. Yao, and J. Jonas, 2007: Will moist convection be stronger in a warmer climate? Geophys. Res. Lett., 34, L16703, https://doi.org/10.1029/2007GL030525.

Dlamini, W. M., 2009: Lightning fatalities in Swaziland: 2000-2007. Nat. Hazards, 50, 179-191, https://doi.org/10.1007/s11069-0089331-6.

Donat, M. G., and Coauthors, 2014: Changes in extreme temperature and precipitation in the Arab region: Long-term trends and variability related to ENSO and NAO. Int. J. Climatol., 34, 581-592, https://doi.org/10.1002/joc.3707.

Doswell, C. A., H. E. Brooks, and R. A. Maddox, 1996: Flash flood forecasting: An ingredients-based methodology. Wea. Forecasting, 11, 560-581, https://doi.org/10.1175/ 1520-0434(1996)011<0560:FFFAIB > 2.0.CO;2.

Emanuel, K. A., 1994: Atmospheric Convection. Oxford University Press, $580 \mathrm{pp}$.

Finney, D. L., R. M. Doherty, O. Wild, D. S. Stevenson, I. A. MacKenzie, and A. M. Blyth, 2018: A projected decrease in lightning under climate change. Nat. Climate Change., 8, 210213, https://doi.org/10.1038/s41558-018-0072-6.

Forster, P. M., and K. P. Shine, 1997: Radiative forcing and temperature trends from stratospheric ozone changes. J. Geophys. Res., 102, 10 841-10 855, https://doi.org/10.1029/96JD03510.

Gijben, M., L. L. Dyson, and M. T. Loots, 2017: A statistical scheme to forecast the daily lightning threat over southern Africa using the Unified Model. Atmos. Res., 194, 78-88, https://doi.org/10.1016/J.ATMOSRES.2017.04.022.

Herrmann, S. M., A. Anyamba, and C. J. Tucker, 2005: Recent trends in vegetation dynamics in the African Sahel and their relationship to climate. Global Environ. Change, 15, 394-404, https://doi.org/10.1016/j.gloenvcha.2005.08.004.

Holzworth, R. H., 2017: World Wide Lightning Location Network. Accessed 28 October 2018, http://wwlln.net/.

Hutchins, M. L., R. H. Holzworth, J. B. Brundell, and C. J. Rodger, 2012: Relative detection efficiency of the World Wide Lightning Location Network. Radio Sci., 47, RS6005, https://doi.org/10.1029/2012RS005049.

IPCC, 2014: Climate Change 2014: Synthesis Report. R. K. Pachauri and L. A. Meyer, Eds., IPCC, 151 pp.

Jenne, R., 1992: Data for reanalysis: Inventories. UCAR, https:// rda.ucar.edu/docs/papers-scanned/pdf/rj0011.pdf.

- and Coauthors, 1993: The NMC/NCAR CDAS/reanalysis project. Office Note 401, 83 pp., https://repository.library.noaa.gov/view/ noaa/11438.

Jiang, J. H., and Coauthors, 2012: Evaluation of cloud and water vapor simulations in CMIP5 climate models using NASA "A-Train" satellite observations. J. Geophys. Res., 117, D14105, https://doi.org/10.1029/2011JD017237.

Kalnay, E., and Coauthors, 1996: The NCEP/NCAR 40-Year Reanalysis Project. Bull. Amer. Meteor. Soc., 77, 437-471, https://doi.org/10.1175/1520-0477(1996)077<0437:TNYRP > 2.0. $\mathrm{CO} ; 2$. 
Khain, A., D. Rosenfeld, and A. Pokrovsky, 2005: Aerosol impact on the dynamics and microphysics of deep convective clouds. Quart. J. Roy. Meteor. Soc., 131, 2639-2663, https://doi.org/ 10.1256/qj.04.62.

Krause, A., S. Kloster, S. Wilkenskjeld, and H. Paeth, 2014: The sensitivity of global wildfires to simulated past, present, and future lightning frequency. J. Geophys. Res. Biogeosci., 119, 312-322, https://doi.org/10.1002/2013JG002502.

Laing, A. G., J. M. Fritsch, and A. J. Negri, 1999: Contribution of mesoscale convective complexes to rainfall in Sahelian Africa: Estimates from geostationary infrared and passive microwave data. J. Appl. Meteor., 38, 957-964, https://doi.org/10.1175/ 1520-0450(1999)038<0957:COMCCT>2.0.CO;2.

Latham, J., 1981: The electrification of thunderstorms. Quart. J. Roy. Meteor. Soc., 107, 277-298, https://doi.org/10.1002/ qj. 49710745202.

Louf, V., C. Jakob, A. Protat, M. Bergmann, and S. Narsey, 2019: The relationship of cloud number and size with their largescale environment in deep tropical convection. Geophys. Res. Lett., 46, 9203-9212, https://doi.org/10.1029/2019GL083964.

Lucas, C., M. A. LeMone, and E. J. Zipser, 1996: Reply. J. Atmos. Sci., 53, 1212-1214, https://doi.org/10.1175/1520-0469(1996) $053<1212: \mathrm{R}>2.0 . \mathrm{CO} ; 2$.

Lynn, B., and Y. Yair, 2010: Prediction of lightning flash density with the WRF model. Adv. Geosci., 23, 11-16, https://doi.org/ 10.5194/adgeo-23-11-2010.

Mary, A. K., and C. Gomes, 2012: Lightning accidents in Uganda. 31st Int. Conf. on Lightning Protection (ICLP), Vienna, Austria, IEEE, https://doi.org/10.1109/ICLP.2012.6344235.

McCaul, E. W., and C. Cohen, 2002: The impact on simulated storm structure and intensity of variations in the mixed layer and moist layer depths. Mon. Wea. Rev., 130, 1722-1748, https://doi.org/ 10.1175/1520-0493(2002)130<1722:TIOSSS >2.0.CO;2.

Mezuman, K., C. Price, and E. Galanti, 2014: On the spatial and temporal distribution of thunderstorm cells. Environ. Res. Lett., 9, 124023, https://doi.org/10.1088/1748-9326/9/12/124023.

Michalon, N., A. Nassif, T. Saouri, J. F. Royer, and C. A. Pontikis, 1999: Contribution to the climatological study of lightning. Geophys. Res. Lett., 26, 3097-3100, https://doi.org/10.1029/ 1999GL010837.

Myhre, G., and Coauthors, 2013: Anthropogenic and natural radiative forcing. Climate Change 2013: The Physical Science Basis, T. F. Stocker et al., Eds., Cambridge University Press, 659-740.

Newell, R. E., J. W. Kidson, D. G. Vincent, and G. J. Boer, 1974: General Circulation of the Tropical Atmosphere and Interactions with Extratropical Latitudes. MIT Press, 320 pp.

Nicholson, S. E., 2000: The nature of rainfall variability over Africa on time scales of decades to millennia. Global Planet. Change, 26, 137-158, https://doi.org/10.1016/S09218181(00)00040-0.

NOAA, 2017: El Niño Southern Oscillation (ENSO). NOAA/ ESRL/PSD, accessed 28 June 2017, https://www.esrl.noaa.gov/ psd/enso/.

Orville, R. E., and Coauthors, 2001: Enhancement of cloud-toground lightning over Houston, Texas. Geophys. Res. Lett., 28, 2597-2600, https://doi.org/10.1029/2001GL012990.

Parrish, D. F., and J. C. Derber, 1992: The National Meteorological Center's spectral statistical-interpolation analysis system. Mon. Wea. Rev., 120, 1747-1763, https://doi.org/10.1175/15200493(1992) $120<1747$ :TNMCSS $>2.0$. CO;2.

Pinto, O., I. R. C. A. Pinto, and M. A. S. Ferro, 2013: A study of the long-term variability of thunderstorm days in southeast Brazil.
J. Geophys. Res. Atmos., 118, 5231-5246, https://doi.org/ 10.1002/JGRD.50282.

Poccard, I., S. Janicot, and P. Camberlin, 2000: Comparison of rainfall structures between NCEP/NCAR reanalyses and observed data over tropical Africa. Climate Dyn., 16, 897-915, https://doi.org/10.1007/s003820000087.

Price, C., 1993: Global surface temperatures and the atmospheric electrical circuit. Geophys. Res. Lett., 20, 1363-1366, https:// doi.org/10.1029/93GL01774.

- 2000: Evidence for a link between global lightning activity and upper tropospheric water vapour. Nature, 406, 290-293, https://doi.org/10.1038/35018543.

_ 2013: Lightning applications in weather and climate research. Surv. Geophys., 34, 755-767, https://doi.org/10.1007/s10712012-9218-7.

_ , and D. Rind, 1994: Possible implications of global climate change on global lightning distributions and frequencies. J. Geophys. Res., 99, $10823-10$ 831, https://doi.org/10.1029/ 94JD00019.

_ an indicator of upper-tropospheric water vapor variability? Bull. Amer. Meteor. Soc., 87, 291-298, https://doi.org/10.1175/ BAMS-87-3-291.

$\longrightarrow$, and 2006b: Inferred long term trends in lightning activity over Africa. Earth Planets Space, 58, 1197-1201, https:// doi.org/10.1186/BF03352010.

—, J. Penner, and M. Prather, 1997: $\mathrm{NO}_{\mathrm{x}}$ from lightning: 1. Global distribution based on lightning physics. J. Geophys. Res., 102, 5929-5941, https://doi.org/10.1029/96JD03504.

_ , Y. Yair, and M. Asfur, 2007: East African lightning as a precursor of Atlantic hurricane activity. Geophys. Res. Lett., 34, L09805, https://doi.org/10.1029/2006GL028884.

_- , and Coauthors, 2011: Using lightning data to better understand and predict flash floods in the Mediterranean. Surv. Geophys., 32, 733-751, https://doi.org/10.1007/s10712-0119146-y.

—_, N. Reicher, and Y. Yair, 2015: Do West African thunderstorms predict the intensity of Atlantic hurricanes? Geophys. Res. Lett., 42, 2457-2463, https://doi.org/10.1002/ 2014GL062932.

Rodger, C. J., 2008: Growing detection efficiency of the World Wide Lightning Location Network. AIP Conf. Proc., 1118, 15, https://doi.org/10.1063/1.3137706.

__ S. Werner, J. B. Brundell, E. H. Lay, N. R. Thomson, R. H. Holzworth, and R. L. Dowden, 2006: Detection efficiency of the VLF World-Wide Lightning Location Network (WWLLN): Initial case study. Ann. Geophys., 24, 3197-3214, https://doi.org/10.5194/angeo-24-3197-2006.

Romps, D. M., J. T. Seeley, D. Vollaro, and J. Molinari, 2014: Projected Increase in lightning strikes in the United States due to global warming. Science, 346, 851-854, https://doi.org/ 10.1126/science.1259100.

—, A. B. Charn, R. H. Holzworth, W. E. Lawrence, J. Molinari, and D. Vollaro, 2018: CAPE times P explains lightning over land but not the land-ocean contrast. Geophys. Res. Lett., $\mathbf{4 5}$, 12 623-12 630, https://doi.org/10.1029/2018GL080267.

Rosenfeld, D., and W. Woodley, 2000: Deep convective clouds with sustained supercooled liquid water down to $-37.5^{\circ} \mathrm{C}$. Nature, 405, 440-442, https://doi.org/10.1038/35013030.

Rowell, D. P., C. K. Folland, K. Maskell, and M. N. Ward, 1995: Variability of summer rainfall over tropical North Africa (1906-92): Observations and modelling. Quart. J. Roy. Meteor. Soc., 121, 669-704, https://doi.org/10.1002/qj.49712152311. 
Rudlosky, S. D., and D. T. Shea, 2013: Evaluating WWLLN performance relative to TRMM/LIS. Geophys. Res. Lett., 40, 2344-2348, https://doi.org/10.1002/grl.50428.

Rutledge, S. A., E. Williams, and T. D. Keenan, 1992: The Down Under Doppler and Electricity Experiment (DUNDEE): Overview and preliminary results. Bull. Amer. Meteor. Soc., 73, 3-16, https://doi.org/10.1175/1520-0477(1992)073<0003: TDUDAE $>2.0 . \mathrm{CO} ; 2$.

Schumann, U., and H. Huntrieser, 2007: The global lightninginduced nitrogen oxides source. Atmos. Chem. Phys., 7, 3823 3907, https://doi.org/10.5194/acp-7-3823-2007.

Seeley, J. T., and D. M. Romps, 2015: The effect of global warming on severe thunderstorms in the United States. J. Climate, 28 , 2443-2458, https://doi.org/10.1175/JCLI-D-14-00382.1.

Takahashi, T., 1978: Riming electrification as a charge generation mechanism in thunderstorms. J. Atmos. Sci., 35, 15361548, https://doi.org/10.1175/1520-0469(1978)035<1536: REAACG $>2.0 . \mathrm{CO} ; 2$.

Taylor, C. M., and Coauthors, 2017: Frequency of extreme Sahelian storms tripled since 1982 in satellite observations. Nature, $\mathbf{5 4 4}$ 475-478, http://doi.org/10.1038/nature22069.

Toracinta, E. R., and E. J. Zipser, 2001: Lightning and SSM/I-icescattering mesoscale convective systems in the global tropics. J. Appl. Meteor., 40, 983-1002, https://doi.org/10.1175/15200450(2001)040<0983:LASIIS > 2.0.CO;2.

Trapp, R. J., N. S. Diffenbaugh, H. E. Brooks, M. E. Baldwin, E. D. Robinson, and J. S. Pal, 2007: Changes in severe thunderstorm environment frequency during the 21st century caused by anthropogenically enhanced global radiative forcing. Proc. Natl. Acad. Sci. USA, 104, 19719-19723, https://doi.org/ 10.1073/pnas.0705494104.

,$- \ldots$, and A. Gluhovsky, 2009: Transient response of severe thunderstorm forcing to elevated greenhouse gas concentrations. Geophys. Res. Lett., 36, L01703, https://doi.org/10.1029/ 2008 GL036203.

Virts, K. S., J. M. Wallace, M. L. Hutchins, and R. H. Holzworth, 2013: Highlights of a new ground-based, hourly global lightning climatology. Bull. Amer. Meteor. Soc., 94, 1381-1391, https://doi.org/10.1175/BAMS-D-12-00082.1.

Wang, C., D. Zheng, Y. Zhang, and L. Liu, 2017: Relationship between lightning activity and vertical airflow characteristics in thunderstorms. Atmos. Res., 191, 12-19, https://doi.org/ 10.1016/J.ATMOSRES.2017.03.003.

Williams, E., 1985: Large-scale charge separation in thunderclouds. J. Geophys. Res., 90, 6013-6025, https://doi.org/ 10.1029/JD090iD04p06013.

- 1992: The Schumann resonance: A global tropical thermometer. Science, 256, 1184-1187, https://doi.org/10.1126/science.256.5060.1184. 1994: Global circuit response to seasonal variations in global surface air temperature. Mon. Wea. Rev., 122, 1917-1929, https:// doi.org/10.1175/1520-0493(1994)122<1917:GCRTSV>2.0.CO;2.
2005: Lightning and climate: A review. Atmos. Res., 76, 272287, https://doi.org/10.1016/j.atmosres.2004.11.014.

— and N. Renno, 1993: An analysis of the conditional instability of the tropical atmosphere. Mon. Wea. Rev., 121, 21-36, https://doi.org/10.1175/1520-0493(1993)121<0021:AAOTCI> 2.0.CO;2.

—, and S. Stanfill, 2002: The physical origin of the land-ocean contrast in lightning activity. C. R. Phys., 3, 1277-1292, https:// doi.org/10.1016/S1631-0705(02)01407-X.

— , and G. Sátori, 2004: Lightning, thermodynamic and hydrological comparison of the two tropical continental chimneys. J. Atmos. Sol.-Terr. Phys., 66, 1213-1231, https://doi.org/ 10.1016/j.jastp.2004.05.015.

, and Coauthors, 1999: The behavior of total lightning activity in severe Florida thunderstorms. Atmos. Res., 51, 245-265, https://doi.org/10.1016/S0169-8095(99)00011-3.

—, K. Rothkin, D. S. Stevenson, and D. Boccippio, 2000: Global lightning variations caused by changes in thunderstorm flash rate and by changes in the number of thunderstorms. J. Appl. Meteor., 39, 2223-2230, https://doi.org/ 10.1175/1520-0450(2001)040<2223:GLVCBC>2.0.CO;2.

— , and Coauthors, 2002: Contrasting convective regimes over the Amazon: Implications for cloud electrification. J. Geophys. Res., 107, 8082, https://doi.org/10.1029/2001JD000380.

- V. Mushtak, D. Rosenfeld, S. Goodman, and D. Boccippio, 2005: Thermodynamic conditions favorable to superlative thunderstorm updraft, mixed phase microphysics and lightning flash rate. Atmos. Res., 76, 288-306, https://doi.org/ 10.1016/j.atmosres.2004.11.009.

, A. Guha, R. Boldi, H. Christian, and D. Buechler, 2019: Global lightning activity and the hiatus in global warming. J. Atmos. Solar-Terr. Phys., 189, 27-34, https://doi.org/10.1016/ J.JASTP.2019.03.011.

Yair, Y., B. Lynn, C. Price, V. Kotroni, K. Lagouvardos, E. Morin, A. Mugnai, and M. del Carmen Llasat, 2010: Predicting the potential for lightning activity in Mediterranean storms based on the Weather Research and Forecasting (WRF) model dynamic and microphysical fields. J. Geophys. Res., 115, D04205, https://doi.org/10.1029/2008JD010868.

Yin, X., and S. E. Nicholson, 1998: The water balance of Lake Victoria. Hydrol. Sci. J., 43, 789-811, https://doi.org/10.1080/ 02626669809492173.

Yoshida, S., T. Morimoto, T. Ushio, and Z. I. Kawasaki, 2009: A fifth-power relationship for lightning activity from Tropical Rainfall Measuring Mission satellite observations. J. Geophys. Res., 114, D09104, https://doi.org/10.1029/2008JD010370.

Ziv, B., H. Saaroni, Y. Yair, M. Ganot, A. Baharad, and D. Isaschari, 2009: Atmospheric factors governing winter thunderstorms in the coastal region of the eastern Mediterranean. Theor. Appl. Climatol., 95, 301-310, https://doi.org/10.1007/s00704-0080008-6. 